\title{
The epidemiology of good nutritional status among children from a population with a high prevalence of malnutrition
}

\author{
Jane A Pryer ${ }^{1,2, *}$, Stephen Rogers ${ }^{1}$ and Ataur Rahman ${ }^{3}$ \\ ${ }^{1}$ Royal Free and University College London Medical School, University College London, Department of Primary Care \\ and Population Sciences, Royal Free Campus, Rowland Hill Street, London NW3 2PF, UK: ${ }^{2}$ International Food Policy \\ Research Institute, Food and Nutrition Division, 2033 K Street, Washington, DC 20006-1002, USA: ${ }^{3}$ Proshika, \\ I/1-GA, Section 2, Mirpur, Dhaka 1216, Bangladesh
}

Submitted 11 March 2003: Accepted 7 August 2003

\begin{abstract}
Objectives: To identify socio-economic demographic and environmental factors that predict better height-for-age for children under 5 years of age in a Dhaka slum population.

Design: A panel survey, conducted between 1995 and 1997. A random sample of households was selected. Socio-economic, demographic and environmental variables were collected monthly by questionnaire and nutritional status was assessed.

Setting: Dhaka slums in Bangladesh.

Subjects: Three hundred and ninety-two children, surveyed in September-November 1996.

Main outcome measures: Height-for-age $Z$-score (HAZ) above -2 .

Results: Thirty-one per cent of children had HAZ $>-2$. Logistic regression adjusted for cluster sampling showed that better nourished children were more likely to have taller mothers, to be from female-headed households and from families with higher income, electricity in the home, better latrines, more floor space and living in Central Mohammadpur. Better nourished children were less likely to have fathers who have taken days off from work due to illness.

Conclusions: Interest in 'positive deviance' is motivated by the recognition that a focus on the malnourished only - the bottom tail of the distribution - provides indications of how families fail, but not of how they succeed in maintaining child nutrition in the face of adversity. Our analysis provides an alternative perspective on nutrition and vulnerability in an urban slum setting.
\end{abstract}

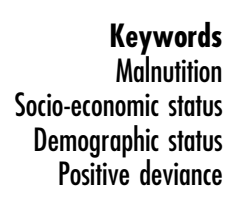

Keywords Malnutition Demographic status Positive deviance
The term 'positive deviance' has been used widely to describe children who do not show evidence of malnutrition, when the majority living in the same environment suffer from malnutrition ${ }^{1}$. Most studies look at risk factors for malnutrition. Several studies conducted in urban areas of developing countries have shown that malnutrition is associated with low income ${ }^{2-5}$, employment status ${ }^{5}$, household expenditure ${ }^{2}$, low education ${ }^{2,6-8}$, housing status ${ }^{8,9}$, sanitation ${ }^{10}$, and demographic variables including household size ${ }^{6}$ and birth order ${ }^{11,12}$. However, the determinants of 'positive deviance' are more than the converse of poor growth. Shekar et al. ${ }^{13}$ hypothesised that the mechanisms operating to produce 'positive deviance' and 'negative deviance' are different. A factor that may be associated with 'negative deviance' need not be inversely associated with 'positive deviance'. In this paper we identify children who have height-for-age $Z$-scores above
-2 , and identify social, economic and demographic factors that predict good height-for-age.

\section{Methods}

\section{Setting}

Dhaka is the national capital and the largest city of Bangladesh. Thirty million people, over $20 \%$ of the total population of Bangladesh, live in urban areas. By the year 2005 this figure will have risen to 46 million, and by 2015 projections indicate that 68 million (more than a third of the total population of Bangladesh) will live in urban areas ${ }^{14,15}$. In the absence of commensurate industrialisation and on the account of little planned urban or spatial development, this rapid expansion of the urban population has serious implications for physical and socioeconomic conditions for the country's cities ${ }^{14,15}$. 
The number of slum settlements has grown rapidly in recent years and the urban poor are now estimated at around 11 million, or $37 \%$ of the urban population ${ }^{16}$. Fourteen per cent of the urban population lives below the poverty line and the largest gap between the rich and the poor is in the urban areas ${ }^{15}$. However, $50 \%$ of the slum population lives below the poverty line ${ }^{17}$.

The Urban Livelihoods Study is based in the slum settlements of Mohammadpur subdistrict of Dhaka City. Agargoan includes the biggest slum in Mohammadpur. The land is owned by the government but has been occupied informally by squatters for over 20 years. Central Mohammadpur includes slums in Rayer Bazaar, Jafrabad, Pisciculture, Adabar and Pulpar Bottola areas. Most of the slums in this area consist of poor housing within middle and lower-middle class residential housing settlements. Private landlords own most, though some are on disputed land. Finally, Beri Badh is the peripheral area of Mohammadpur. The settlements have been developed along the embankment of the Dhaka City Flood Protection, alongside the Buri Ganga River. The embankment is government-owned land, with slums adjacent to the embankment situated on privately owned land.

\section{Study design}

Data collection is based on two sets of interrelated activities: quantitative data collection on a panel of around 850 households - termed the quantitative panel survey and qualitative studies which explore the same study objectives within selected slum settlements in the study area. Panel households were selected through a random cluster sample of all slum areas in Mohammadpur, with stratification for geographical area. Twenty-five clusters of households were sampled across Mohammadpur subdistrict.

Sample size was calculated using standard statistical formulae at the outset of the study, on the basis of being able to detect differences in adults and children between socio-economic groups of the population. The sample size was inflated to allow for the fact that cluster sampling was employed. The process suggested that the sample should be at least 700 households.

Households were followed up on a monthly basis. The monthly questionnaire was administered to the head of household and spouse, and enquiries were made into work participation, sources of income, changes in financial status, shocks, stresses, coping strategies and food expenditure. Acute and work-disabling morbidity was recorded for a 2 -week recall period and anthropometry was carried out on the household head, spouse and children below 5 years of age.

Every third month a more extensive data collection interview took place, this time involving the head of household, spouse and all resident family members. At this interview detailed additional information was collected on debts and savings, income from employment and other sources, asset ownership, sale and purchase, food supply and food stocks, food expenditure, total expenditure, child feeding practices, common property resource use, social relations (trades union/committee/non-governmental organisation membership and activities), use of amenities and environmental situation. Changes in financial status, self-reported morbidity and anthropometry were documented for all household members.

Quality assurance was a high priority. Every week, supervised interviews, re-interviews and spot checks were conducted and supervisors checked that questionnaires were completed properly. Age of the mother was assessed using a marriage questionnaire, in which she was asked her age when she started to live with her partner, age when she got married and age at each birth, and finally her current age. There was good agreement (within 6 months) between the calculated age from the marital questionnaire and declared current age. Consumption units were calculated using a standard method based upon energy requirements of men and women of different ages (see Appendix). Double entry of the data was done to minimise errors in data entry.

\section{Statistical analysis}

The analysis draws on data collected from the quantitative panel survey conducted during September-November 1996. Complete data were collected on one occasion during the 3-month period (the '3-monthly round'). Individual child-specific nutritional status was based on height-for-age $Z$-score (HAZ), with children having HAZ $>-2$ (better nutritional status) being compared with the remainder (HAZ $<-2$, worse nutritional status). The independent variables were organised into groups approximating quartiles, to allow for the identification of non-linear relationships in a statistically powerful way. Chi-square and $t$-tests were carried out to test for differences between children with better and worse nutritional status. We then used logistic regression with adjustment for clustering, the SVYLOGIT command in Stata, to identify independent predictors (Stata Corp., College Station, TX, USA, 2002). The risk factors that showed statistically significant or close to significant associations were entered into the logistic regression. The logistic regression model incorporated child's age in months, income, savings per consumption unit, mother's height, parity, gender of household head, area of residence, room height, type of child's latrine, electricity in the home, floor area, father's working days off due to illness, mother's home days off due to illness and dry season's cooking location as independent variables, with $\mathrm{HAZ}>-2$ as the dependent outcome.

\section{Results}

Table 1 shows economic variables for better and worse nutritional status. Income and loans were higher for 
Table 1 Economic variables by worse $(H A Z<-2)$ and better $(H A Z>-2)$ nutritional status in children

\begin{tabular}{|c|c|c|c|c|}
\hline Variable & $n$ & Mean & $\begin{array}{l}95 \% \text { confidence } \\
\text { interval }\end{array}$ & $P$-value \\
\hline \multicolumn{5}{|c|}{ Income (Taka) } \\
\hline Worse & 266 & 2764.80 & $2594.20-2935.40$ & \multirow[t]{2}{*}{0.034} \\
\hline Better & 126 & 4492.18 & $1793.50-7190.70$ & \\
\hline \multicolumn{5}{|c|}{ Loans (Taka) } \\
\hline Worse & 266 & 1697.83 & $731.39-2664.27$ & \multirow[t]{2}{*}{0.0106} \\
\hline Better & 126 & 2507.14 & $688.11-4326.15$ & \\
\hline \multicolumn{5}{|c|}{ Food expenditure per CU (Taka) } \\
\hline Worse & 266 & 61.59 & $49.61-73.57$ & \multirow[t]{2}{*}{0.9622} \\
\hline Better & 126 & 62.24 & $37.12-87.36$ & \\
\hline \multicolumn{5}{|c|}{ Total expenditure per CU (Taka) } \\
\hline Worse & 266 & 196.71 & $169.15-224.27$ & \multirow[t]{2}{*}{0.4473} \\
\hline Better & 126 & 200.87 & $146.03-255.70$ & \\
\hline \multicolumn{5}{|c|}{ Business assets (Taka) } \\
\hline Worse & 266 & 1697.83 & $731.39-2664.27$ & \multirow[t]{2}{*}{0.1982} \\
\hline Better & 126 & 2507.13 & $688.11-4326.15$ & \\
\hline \multicolumn{5}{|c|}{ Savings per CU (Taka) } \\
\hline Worse & 266 & 1032.57 & $661.31-2726.44$ & \multirow[t]{2}{*}{0.021} \\
\hline Better & 126 & 201.80 & $107.15-510.75$ & \\
\hline
\end{tabular}

$\mathrm{HAZ}$ - height-for-age Z-score; CU - consumption unit.

children with better nutritional status, compared with children with worse nutritional status. Food expenditure per consumption unit, total expenditure per consumption unit, business assets and savings per consumption unit were higher in better nourished children, but these were not significant.

Table 2 shows mother and father's characteristics and other variables for children with better and worse nutritional status. There were no differences between mother's age, head of household's occupation and mother or father's education level for children with better or worse nutritional status. Mother's height and weight were higher in children with better nutritional status than in children with worse nutritional status. Mother's home days off due to illness were more in children who had better nutritional status compared with those who had worse nutritional status. Father's work days off were less in children with better nutritional status than in children who had worse nutritional status. Children with better nutritional status were more likely to come from Agargoan and Central Mohammadpur, and children with worse nutritional status were more likely to come from Beri Badh. There was a higher proportion of female-headed households represented amongst children with better nutritional status compared with children who had worse nutritional status. The proportion of households with breakeven or surplus money was higher in children with better nutritional status, compared with households where children had worse nutritional status, but this was not significant.

Table 3 shows children's characteristics and environmental variables by nutritional status. Children with better nutritional status were more likely to be younger. A higher proportion of children with better nutritional status used a good latrine, whereas more children with worse nutritional status used an open latrine. A slightly higher proportion of children with better nutritional status drank tap water, compared with poorer nutritional status children who drank water from a tube well, but this was not significant. A lower percentage of children with better nutritional status than of children with worse nutritional status came from a home where cooking took place in the sleeping room. Moreover, children with better nutritional status were more likely to live in complete tin, complete brick or combination homes than were children with poor nutritional status, who lived in houses with katcha (thatched) walls and tin roofs, although this was not significant.

Table 4 illustrates the results of logistic regression analysis for economic, demographic and environmental factors relating to better nutritional status in children. The odds of better nutritional status in older children were less than in younger children. Regarding total income, the odds for better nutritional status were higher at higher income levels. The odds for better nutritional status were higher where savings were less. Odds for better nutritional status were higher for taller mothers, and also higher for mothers with two or three children. Female-headed households had higher odds for better nutritional status compared with male-headed households. Odds were higher when children lived in Central Mohammadpur, compared with Agargoan and Beri Badh. Odds for room height, electricity in the home and floor area were all significantly related to better nutritional status in children. Odds for better nutritional status were less for father's work days off due to illness. Mother's home days off due to illness was significantly related to better nutritional status. Finally, the odds for better nutritional status were higher where cooking was done outside the living area.

\section{Discussion}

In this community in Dhaka slums there was a very high prevalence of malnutrition. The prevalence of stunting was $68.4 \%$, that of wasting was $31.2 \%$ and underweight prevalence was $73.2 \%$. The prevalence of malnutrition is higher in Dhaka slums than the national average, which is $49 \%$ for stunting, $17.5 \%$ for wasting and 56\% for underweight, and indicates exceptionally high levels of malnutrition as judged against World Health Organization criteria $^{18}$.

Many socio-economic variables have been shown to be associated with malnutrition ${ }^{2,3,5,8}$. In this study, the families of children with good nutritional status were more likely to report surplus money in response to a question on financial status. We also found that food expenditure per consumption unit above the baseline was significantly related to better nutritional status, although savings per consumption unit was negatively related to better nutritional status (meaning that as savings were 
Table 2 Mother's and father's characteristics and other variables by worse $(\mathrm{HAZ}<-2)$ and better (HAZ $>-2)$ nutritional status in children

\begin{tabular}{|c|c|c|c|c|}
\hline \multirow[b]{2}{*}{ Variable } & \multirow{2}{*}{$\frac{\text { Worse }(n=266)}{n(\%)}$} & \multirow{2}{*}{$\frac{\text { Better }(n=126)}{n(\%)}$} & \multirow[b]{2}{*}{$x^{2}$} & \multirow[b]{2}{*}{$P$-value } \\
\hline & & & & \\
\hline \multicolumn{5}{|l|}{ Mother's age (years) } \\
\hline $17-21$ & $67(25)$ & $26(20)$ & 5.252 & 0.154 \\
\hline $22-24$ & $60(22)$ & $20(15)$ & & \\
\hline $25-29$ & $68(26)$ & $44(34)$ & & \\
\hline $30-50$ & $71(27)$ & $32(25)$ & & \\
\hline \multicolumn{5}{|l|}{ Mother's height $(\mathrm{cm})$} \\
\hline $135.2-144.9$ & $71(26)$ & $19(15)$ & 10.082 & 0.018 \\
\hline $145-148.9$ & $68(25)$ & $26(20)$ & & \\
\hline $149-151.9$ & $57(21)$ & $35(28)$ & & \\
\hline $152-166$ & $57(21)$ & $38(30)$ & & \\
\hline \multicolumn{5}{|l|}{ Mother's weight (kg) } \\
\hline $28.8-37$ & $73(27)$ & $20(16)$ & 9.5417 & 0.023 \\
\hline $37.1-40.9$ & $57(21)$ & $35(28)$ & & \\
\hline $41-44.9$ & $64(24)$ & $25(20)$ & & \\
\hline $45-60$ & $54(20)$ & $36(29)$ & & \\
\hline \multicolumn{5}{|c|}{ Mother's home days off due to disabling illness } \\
\hline $0-1$ & $190(71)$ & $70(55)$ & 8.5619 & 0.031 \\
\hline $2-10$ & 63 (23) & $45(35)$ & & \\
\hline $11-28$ & $13(4)$ & $11(8)$ & & \\
\hline \multicolumn{5}{|l|}{ Mother's educational level } \\
\hline No schooling & $166(62)$ & $80(70)$ & 0.4368 & 0.979 \\
\hline 1 year of schooling & $3(3)$ & $3(3)$ & & \\
\hline $2-3$ years of schooling & $3(3)$ & $2(2)$ & & \\
\hline $3-5$ years of schooling & $55(22)$ & $23(20)$ & & \\
\hline $6+$ years of schooling & $12(5)$ & $6(5)$ & & \\
\hline \multicolumn{5}{|l|}{ Area of residence } \\
\hline Agargoan & $121(45)$ & $64(51)$ & 9.1993 & 0.027 \\
\hline Central Mohammadpur & $88(33)$ & $50(39)$ & & \\
\hline Beri Badh & $52(12)$ & $12(9)$ & & \\
\hline \multicolumn{5}{|l|}{ Head of household's gender } \\
\hline Male & $252(94)$ & $104(83)$ & 7.7501 & 0.049 \\
\hline Female & $14(5)$ & $20(16)$ & & \\
\hline \multicolumn{5}{|l|}{ Financial status (last month) } \\
\hline Very short of money & $85(32)$ & $29(23)$ & 5.6142 & 0.132 \\
\hline Short of money & $82(31)$ & $36(29)$ & & \\
\hline Broke even & $88(33)$ & $52(41)$ & & \\
\hline Surplus money & $11(4)$ & $9(7)$ & & \\
\hline \multicolumn{5}{|l|}{ Father's work days off due to illness } \\
\hline 0 & $76(29)$ & $26(21)$ & 7.850 & 0.0474 \\
\hline $1-30$ & $190(71)$ & $100(79)$ & & \\
\hline \multicolumn{5}{|l|}{ Head of household's occupation } \\
\hline Regular salaried worker & $13(4)$ & $10(7)$ & 7.4964 & 0.186 \\
\hline Casual wage worker (skilled) & $21(7)$ & $14(11)$ & & \\
\hline Casual wage worker (unskilled) & $39(14)$ & $8(6)$ & & \\
\hline Dependent self-employed & $65(24)$ & $29(23)$ & & \\
\hline Self-employed & $103(38)$ & 49 (39) & & \\
\hline Family worker (unpaid) & $3(1)$ & $2(1)$ & & \\
\hline
\end{tabular}

HAZ - height-for-age Z-score.

higher nutritional status was less likely to be good). In a previous analysis examining 'negative deviance' (HAZ $\leq-3$ as dependent variable), families with malnourished children reported a deficit financial situation, although no relationship was demonstrated with food expenditure or savings ${ }^{17}$.

Pryer previously used cluster analysis to identify livelihood groups in this population ${ }^{17}$. Twenty per cent of households in the richest group lost labour days, compared with $44 \%$ in the poorest group. In the poorest group income lost amounted to $30 \%$ of household income, and in the richest group around 11\% of income. Mother's illness resulted in 5 days at home in the poorest group, and 3 days in the richest group ${ }^{17}$. In this analysis, number of father's days off due to illness was negatively related to better nutritional status. We suggest that this might be indicative of an important link between father's illness and household income. Interestingly, mother's home days off due to illness was significantly related to better nutritional status in our logistic regression model. The reasons for this are not known. In previous analyses to examine 'negative deviance' (HAZ $\leq-3$ ), neither father's work days off due 
Table 3 Children's characteristics and environmental variables by worse (HAZ $<-2)$ and better $(\mathrm{HAZ}>-2)$ nutritional status in children

\begin{tabular}{|c|c|c|c|c|}
\hline & Worse $(n=266)$ & Better $(n=126)$ & & \\
\hline Variable & $n(\%)$ & $n(\%)$ & $x^{2}$ & $P$-value \\
\hline \multicolumn{5}{|l|}{ Child's age (months) } \\
\hline $3-15$ & $37(14)$ & $46(36)$ & 27.880 & 0.0001 \\
\hline $16-30$ & $82(31)$ & $23(18)$ & & \\
\hline $31-44$ & $71(27)$ & $31(25)$ & & \\
\hline $45-59$ & $76(29)$ & $26(20)$ & & \\
\hline \multicolumn{5}{|l|}{ Child's latrine type } \\
\hline Very good & $10(4)$ & $4(3)$ & 7.8562 & 0.049 \\
\hline Good & $21(8)$ & $21(16)$ & & \\
\hline Unhygienic & $100(38)$ & 48 (38) & & \\
\hline Open/anywhere & $114(43)$ & $43(34)$ & & \\
\hline \multicolumn{5}{|l|}{ Source of drinking water } \\
\hline Tap & $126(47)$ & $68(54)$ & 1.3818 & 0.240 \\
\hline Tube well & $123(46)$ & $51(40)$ & & \\
\hline \multicolumn{5}{|l|}{ Dry season's cooking location } \\
\hline Kitchen & $21(8)$ & $6(5)$ & 13.6116 & 0.034 \\
\hline Other rooms & 38 (14) & $25(20)$ & & \\
\hline Sleeping room & $94(35)$ & $38(30)$ & & \\
\hline Near home & $84(32)$ & 39 (31) & & \\
\hline Other location & $12(5)$ & $7(6)$ & & \\
\hline \multicolumn{5}{|l|}{ Housing construction } \\
\hline Complete katcha & $60(23)$ & $29(23)$ & 4.3962 & 0.222 \\
\hline Katcha wall \& tin roof & $154(58)$ & $64(50)$ & & \\
\hline Complete tin & $13(4)$ & $12(9)$ & & \\
\hline Complete brick or combination & $22(8)$ & $14(11)$ & & \\
\hline
\end{tabular}

HAZ - height-for-age Z-score.

to illness nor mother's home days off due to illness was related to worse nutritional status ${ }^{17}$.

We found a strong and consistent relationship between mother's height and better nutritional status in children. Rahman et al. $^{19}$ also indicated that maternal nutritional status was related to children's nutritional status in Dhaka after controlling for socio-economic variables and breastfeeding. Mother's nutritional status might be used as a proximate determinant for children's nutritional status. For example, Islam et al. ${ }^{10}$ conducted a case-control study in Dhaka, looking at maternal and socio-economic factors and the risk of severe malnutrition in children. Short mothers and malnourished mothers were more likely to have a malnourished child, and the investigators argued that maternal malnutrition may be a useful indicator to identify families at risk of severe malnutrition.

Parity was significantly associated with better nutritional status for one and two children, although there was no relationship between parity and stunting in another study ${ }^{17}$. Mozumber et al. ${ }^{20}$ previously studied the effects of birth interval on children's nutritional status in Bangladesh. The percentage of malnourished children decreased as the birth interval increased. Alam ${ }^{21}$ studied the effect of birth interval on child and infant mortality, finding that if the preceding birth interval was less than 15 months, this was associated with greater mortality in the post-neonatal period. A pregnancy interval of less than 12 months after childbirth raised the risk of death at age 1-2 years considerably, compared with children born after a birth interval of more than 15 months.
We also found that female-headed households are more likely to accommodate better nutritional status. It might be suggested that female-headed households are more likely to have children with better nutritional status than are male-headed households because women are in charge of the budget, are more child-centred, can buy better food for the child and take the child to clinic when it is ill. We note, however, that there are differences with other analyses, perhaps because we have controlled for economic factors in our regression analysis (female-headed households tend to be poorer $)^{22,23}$.

Home environmental factors, such as electricity, room height and floor area, are all associated with better nutritional status. The factors were not associated with worse nutritional status. Latrine use by children has been associated with malnutrition in many studies ${ }^{3,10}$. Nonsanitary latrines were associated with stunting in a previous analysis $^{17}$. In this study, children's use of sanitary latrines was significantly associated with better nutritional status.

It is widely acknowledged that socio-economic development will not alleviate poverty in developing countries over the next few decades. The number of malnourished children is still very high in Bangladesh. From a scientific point of view, interest in 'positive deviance' continues to be motivated by the recognition that a focus on the malnourished only - the bottom tail of the distribution provides indications of how families fail, but not of how they succeed in maintaining child nutrition in the face of adversity. In this respect our findings have been illustrative. 
Table 4 Logistic regression for better nutritional status (HAZ $>-2)$ in children, by economic, demographic and environmental variables $(n=392)$

\begin{tabular}{lccc}
\hline & Adjusted & Standard & \\
Variable & odds ratio & error & $P$-value
\end{tabular}

Child's age (months)

$3-15$

$16-30$

$31-44$

$$
\text { 45-59 }
$$

1

$\begin{array}{lll}0.64 & 0.45 & 0.001\end{array}$

$\begin{array}{lll}0.91 & 0.74 & 0.0003\end{array}$

Total income (Taka)

1096

1097-2193

2194-3288

3289-4384

0.41

0.04

1

1.15

1.75

2.97

0.50

0.53

0.90

Savings per CU (Taka)

1.0-102

103.5-66 000

Mother's height $(\mathrm{cm})$

135.2-144.9

145-148.9

149-151.9

$152-166$

Parity

1

2

3

4-10

Head of household's gender

Male

Female

Area of residence

Agargoan

Central Mohammadpur

Central Mohammadpu

eri Badh

Room height

Standing

Not standing

Child's latrine type

Very good

Good

Unhygienic

Open/anywhere

1

$-1.20$

0.41

0.004

1

0.25

1.62

1.49

1

5.90

7.51

4.83

0.53

0.60

0.53

0.643

0.008

0.006

6.01

5.79

5.56

0.081

0.074

0.171

1

2.94

1.27

0.021

6.71
0.61

5.29

0.45

0.015

0.503

1

1.11

1.20

0.055

1

1.70

1.07

0.76

0.94

0.93

0.92

1

3.57

2.22

0.041

Floor area $\left(\mathrm{m}^{2}\right)$

$1.25-6.2$

$6.3-8.4$

$8.5-11.7$

$11.8-40.2$

1

1.31

1.29

1.34

0.57

0.61

0.63

0.022

0.035

0.33

Father's work days off due to illness

0

2-10

$11-28$

1
-1.18

$-1.80$

0.48

0.85

0.015

0.035

Mother's home days off due to illness

0

2-21

1

1.16

0.55

0.033

Dry season's cooking location

Kitchen

Other rooms

Sleeping room

Near home

Other location
1

1.38

1.27

1.13

2.17
0.125

0.109

0.135

\section{Conclusions}

In this study of nutritional status among children of a population with a high prevalence of malnutrition, 'positive deviance' was characterised by taller mothers, less parity, female-headed households, higher income, electricity in the home, more floor area and living in a better neighbourhood. There was also a negative association with father's work days off due to illness. Our analysis provides an alternative perspective on nutrition and vulnerability in an urban slum setting.

\section{Acknowledgements}

This study was sponsored by the Department of International Health (UK). The authors thank Dr Marie Ruel and Dr James Garrett for invaluable comments on this paper.

\section{Urban Liveliboods Study}

The Urban Livelihoods Study (ULS) Team includes:

ULS Steering Committee

Dr Qazi Faruque Ahmed (Proshika Co-Chair), Dr Jane Pryer (LSHTM Co-Chair), Dr Geoff Wood, Mr Shahabuddin, Dr Sarah Salway, Mr Iqbal Alam Khan, Mr Matthew Kiggins, Mr Mahbubul Karim, Professor Nazrul Islam and Dr Oona Campbell.

\section{Bangladesh Team Members}

- Bangladesh Project Director: Mr Md Shahabuddin

- Project Co-ordinator (Qualitative): Mr Iqbal Alam Khan

- Qualitative Researchers: Ms Sonia Jesmin, Mr Azmal Kabir Kazal, Ms Mottahera Nasrin, Mr AEA Opel

- Quantitative Research Officers: Dr Ataur Rahman, Ms Shahana Rahman

- Database Manager: Mr Mostafa el Helal

- Supervisors: Mr SM Zubair Ali Khan, Mr Akramul Islam

- Interviewers: Mr Shahajahan Hossain, Ms Rifat Aara, Mr Md Salim, Ms Dilafroze, Ms Rezina Khan Ratna, Ms Rafeza Shaheen, Mr Patrick Rozario, Ms Afsari Begum, Mr Tasbir-ul-Hasnain, Mr Moniruzzaman, Mr Md Ataul Islam, Mr Dayal Chandra Das, Mr Golam Firoz, Ms Nurun Nahar, Ms Namita Chakravarti, Mr Chandon Banik, Mr Mustafiz Ali Khan, Ms Shahina Khan, Ms Asma Begum, Mr Mahbubal Alam

- Data Entry Clerks: Mr Md Helaluddin Farid, Ms Nargis Akter, Mr Md Sohel Ahmed Tarafder, Ms Monira Islam

- Mapping Team: Ms Rifat Aara, Mr Arif Hossain Khan, Mr Md Mainul Islam

London Team Members

0.017

HAZ - height-for-age Z-score; CU - consumption unit.

- Team Leader: Dr Jane Pryer

- Project Co-ordinator (Quantitative): Dr Sarah Salway

- Project Co-ordinator (Epidemiology): Mr Matthew Kiggins 
- Epidemiology Adviser: Dr Oona Campbell

Bath Team Members

- Qualitative Adviser: Dr Geoff Wood

- Student Placement: Ms Emily Delap

\section{References}

1 Zeitlin M. Nutritional resilience in a hostile environment: positive deviance in child nutrition. Nutrition Reviews 1991; 49(9): 259-68.

2 Engle PL. Influences of mother's and father's income on children's nutritional status in Guatemala. Social Science $\&$ Medicine 1993; 37(11): 1303-12.

3 Huttly SRA, Victora CG, Barros FC, Teixeira AMB, Vaughn PJ. The timing of nutritional status determination: implications for interventions and growth monitoring. European Journal of Clinical Nutrition 1991; 45: 85-95.

4 Khin-Maung U, Khin M, Wai NN, Hman NW, Myint TT, Butler T. Risk factors for the development of persistent diarrhoea and malnutrition in Burmese children. International Journal of Epidemiology 1992; 21(5): 1021-9.

5 Pryer JA. Socio-economic and environmental aspects of undernutrition and ill-bealth in an urban slum in Bangladesh. PhD thesis, University of London, London, 1990.

6 Doan RM, Bishatarat L. Female autonomy and child nutritional status: the extended family residential unit in Aman. Social Science \& Medicine 1990; 31(7): 783-9.

7 Lima M, Figuira MD, Ebrahim GJ. Malnutrition among children of adolescent mothers in a squatter community of Redclife, Brazil. Journal of Tropical Paediatrics 1990; 36: 14-9.

8 Ricca JA, Becker S. Risk factors for wasting and stunting among children in Metro Cebu, Philippines. American Journal of Clinical Nutrition 1996; 63: 966-75.

9 Thaver IH, Ebrahim GJ, Richardson R. Infant mortality and undernutrition in the squatter settlements of Karachi. Journal of Tropical Paediatrics 1990; 36: 135-40.

10 Islam MA, Rahman MM, Mahalanabis D. Maternal and socio-economic factors and the risk of a severe malnutrition in a child: a case-control study. European Journal of Clinical Nutrition 1994; 48: 416-24.

11 Engle PL. Maternal work and child care strategies in periurban Guatemala: nutritional effects. Child Development 1991; 62(5): 954-65.

12 Jongpiputvanich S, Poomsuwan P, Phittayanon P. Prevalence and risk factors of protein energy malnutrition (PEM) in preschool children of Klong-Toey slum, Bankok, Thailand. Journal of the Medical Association of Thailand 1992; 75(1): 39-44.

13 Shekar M, Habicht JP, Latham MC. Is positive deviance in growth simply the converse of negative deviance? Food and Nutrition Bulletin 1991; 13(1): 7-11.

14 Government of Bangladesh. Report of the Task Forces on Bangladesh Development Strategies for the 1990s. Vol. 3.
Developing the Infrastructure. Dhaka: Government of Bangladesh, 1992.

15 World Bank. Entering the 21st Century. World Development Report, 1999/2000. Oxford: Oxford University Press, 1999.

16 Islam N, ed. Addressing the Urban Poverty Agenda in Bangladesh. Dhaka: Asian Development Bank/University Press Ltd, 1997.

17 Pryer JA. Investing in children's nutritional status. In: Pryer JA, ed. Poverty and Vulnerability in Dhaka Slums: The Urban Livelibood Study. Aldershot, UK: Ashgate, 2003.

18 Food and Agriculture Organization (FAO)/World Health Organization (WHO). International Conference on Nutrition (Final Report 1992). Rome: FAO/WHO, 1992; 9-55.

19 Rahman M, Roy SK, Ali M, Mitra AK, Alam AN, Akbar MS. Maternal nutritional status as a determinant of child health. Journal of Tropical Paediatrics 1993; 39(2): 86-8.

20 Mozumber AB, Barkat EK, Kane TT, Levein A, Ahmed S. The effects of birth interval on malnutrition in Bangladeshi infants and young children. Journal of Biosocial Science 2000; 32(3): 289-300.

21 Alam N. Birth spacing and infant and early childhood mortality in a high fertility area of Bangladesh: age dependent and interactive effects. Journal of Biosocial Science 1995; 27(4): 393-404.

22 Rogers BL. The implications of female household headship for food consumption and nutritional status in the Dominican Republic. World Development 1996; 24(1): 113-28.

23 Johnson FC, Rogers BL. Children's nutritional status in female headed households in Dominican Republic. Social Science \& Medicine 1993; 37(11): 1293-301.

\section{Appendix - Derivation of consumption units}

The technique of converting households to consumption units based upon energy requirements allows one to standardise households of varying size and sex distribution for comparative purposes. Consumption units are used only in a relative sense. The units in the table below have been derived from the Indian Council of Medical Research Dietary Allowances for Indians. The consumption unit is based upon a moderately active man.

\begin{tabular}{lccc}
\hline Age (years) & Sex & kcal day $^{-1}$ & $\begin{array}{c}\text { Consumption } \\
\text { unit }\end{array}$ \\
\hline$>15$ & Male & 2800 & 1.0 \\
& Female & 2300 & 0.82 \\
$10-14$ & Male & 2300 & 0.82 \\
& Female & 2100 & 0.75 \\
$6-9$ & Male and female & 1800 & 0.64 \\
$<5$ & Male and female & 1350 & 0.48 \\
\hline
\end{tabular}

